\title{
Los libros donados por el primer conde de Haro al Hospital de la Vera Cruz de Medina de Pomar: un testimonio de la bibliofilia de un magnate en la Castilla de mediados del siglo $\mathrm{XV}^{*}$
}

\author{
The books donated by the first count of Haro to the Vera Cruz \\ Hospital in Medina de Pomar: a testimony of a magnate's bi- \\ bliophilia in mid-fifteenth century Castile
}

\author{
Diego Arsuaga Laborde**
}

\begin{abstract}
RESUMEN
El presente artículo tiene por objeto el análisis del inventario de los libros donados en 1455 por Pedro Fernández de Velasco (1401-1470), primer conde de

Haro, al Hospital de la Vera Cruz de Medina de Pomar, cuyos manuscritos se custodian en la actualidad en los fondos documentales de la Biblioteca Nacional de España. Dichas obras, de materia religiosa, moral, profana, jurídica e histórica, testimonian la bibliofilia del conde. Asimismo, representan, en la Castilla de mediados del siglo XV, una clave para comprender el período denominado «fin de la Edad Media, o bien, pórtico del Renacimiento».
\end{abstract}

\section{PALABRAS CLAVE}

Castilla; mediados del siglo XV; Pedro Fernández de Velasco, primer conde de Haro; inventario; libros; Hospital de la Vera Cruz de Medina de Pomar.

\begin{abstract}
The aim of this article is to analyse the inventory of books donated in 1455 by Pedro Fernández de Velasco (1401-1470), first count of Haro, to the Vera Cruz Hospital of Medina de Pomar. The original manuscripts are currently found in the collection of the Biblioteca Nacional de España (National Library of Spain). These books of religious, moral, profane, juridical and historical nature reveal the count's bibliophilia. Moreover, in mid-fifteenth century Castile, they are key to understanding what is known as the end of the Middle Ages or the gateway to the Renaissance.
\end{abstract}

\section{KEY WORDS}

Castile; Mid-fifteenth century; Pedro Fernández de Velasco, First count of Haro; Inventory; Books; Vera Cruz Hospital in Medina de Pomar.

* Fecha de recepción del artículo: 2012-1-25. Fecha de aceptación del artículo: 2012-3-14.

** Becario de FPI-UNED. Departamento de Historia Medieval y Ciencias y Técnicas Historiográficas. UNED. Ce: darsuaga@bec.uned.es 


\section{INTRODUCCIÓN}

La colección inicial de libros del Hospital de la Vera Cruz de Medina de Pomar ha sido analizada, entre otros investigadores, por Antonio Paz y Meliá, Julián de San Pelayo, Julián García Sáinz de Baranda, Esther González Crespo y Jeremy Lawrance.

Antonio Paz y Meliá, en su estudio de la mencionada colección¹, analizó un documento, custodiado en los fondos de la Biblioteca Nacional de España (BNE), con la signatura siguiente: BNE, RES/141. Se trata de un documento, otorgado el 27 de mayo de 1553 por un heredero y sucesor del primer conde de Haro, Juan Fernández de Velasco, que contiene tres apartados. El primero (fols. 1r-19v) incluye un catálogo de las obras que custodiaba, en aquel entonces, el hospital. El segundo (fols. 20r22v) contiene un inventario de los libros donados en 1455 por el conde a la institución asistencial. $Y$ en el tercero (fols. 22v-25r), Pedro Fernández de Velasco encarga a sus herederos y sucesores «porque el servicio de / Nuestro Señor sea siempre aumentado e / acrecentado en el dicho hospital»². Pero Paz y Meliá únicamente tuvo presente el apartado primero, y anotó un total de ciento sesenta obras.

Julián de San Pelayo, como réplica al contenido de las investigaciones publicadas hasta entonces por Paz y Meliá sobre la dotación de libros ${ }^{3}$, observó que no todos los libros apuntados en el apartado primero del citado documento se remontaban al año de la colección inicial de obras, y manifestó que publicaría un catálogo de la referida colección. Por tal motivo, Antonio Paz y Meliá estimó la idoneidad de suspender, de momento, la publicación del artículo que tenía previsto, confiando en que el mencionado catálogo, «por su prioridad, modificaría ventajosamente o acaso anularía el mío»4. Finalmente, don Julián no publicó el inventario y don Antonio, en 1909, completó la publicación de su artículo.

Por otra parte, en 1917 Julián García Sáinz de Baranda, en su estudio sobre la ciudad de Medina de Pomar ${ }^{5}$, efectuó una transcripción del catálogo de la dotación de libros, incluido en el documento, probablemente original, de las ordenanzas otorgadas el 14 de agosto de 1455 por el primer conde de Haro a la institución asistencial. En la transcripción del inventario anotó un total de setenta y seis obras. No obstante, la transcripción la realizó sin una tarea de identificación y comentario de los libros.

\footnotetext{
1 PAZ Y MELIÁ, A.: «Biblioteca fundada por el conde de Haro en 1455». Revista de Archivos, Bibliotecas y Museos (RABM), 1, (1897), págs. 18-24, 60-66, 156-163, 255-262, 452-462; RABM, 4, (1900), págs. 535-541, 662-667; RABM, 6, (1902), págs. 198-206, 372-382; RABM, 7, (1902 bis), págs. 51-55; RABM, 19, (1908), págs. 124-136; RABM, 20, (1909), págs. 277-289.

2 BNE, RES/141, fol. 22v.

3 SAN PELAYO, J. de: «La biblioteca del buen conde de Haro. Carta abierta al Sr. D. Antonio Paz y Mélia». RABM, 8, (1903), págs. 182-193; RABM, 9, (1903 bis), págs. 124-139.

4 PAZ Y MÉLIA, A.: «Biblioteca fundada por el conde de Haro en 1455». RABM, 19, (1908), pág. 135.

5 GARCÍA SÁINZ DE BARANDA, J.: Apuntes históricos sobre la ciudad de Medina de Pomar. Burgos, El Monte Carmelo, 1917.
} 
Posteriormente, Esther González Crespo, en su tesis doctoral sobre la Casa de Velasco ${ }^{6}$, también alude a la colección de obras. Concretamente, en uno de los epígrafes dedicados al conde, siguiendo a García Sáinz de Baranda, se refiere al catálogo de la citada colección, en el que identifica y glosa sucintamente determinados libros.

Fue en 1984 cuando Jeremy Lawrance realiza un estudio exhaustivo de la dotación de obras ${ }^{7}$, analizando el documento consultado por Paz y Meliá antes indicado. Comprueba que el apartado primero contiene el inventario del apartado segundo y, asimismo, el catálogo de los libros que «se han man- / -dado poner en la dicha librería por los señores / de la gran Casa de Velasco y sus succesores». Por lo tanto, confirma que no todos las obras apuntadas en el apartado primero proceden de la colección inicial de libros. Seguidamente, encuentra el inventario de dicha colección en el apartado segundo. A diferencia de las obras anotadas en el apartado primero, que ascienden a un total de ciento sesenta, apunta en el apartado segundo un total de setenta y nueve libros. En tal estudio, identifica y comenta las obras incluidas en ambos apartados.

Por lo tanto, las investigaciones realizadas sobre la dotación inicial de libros del hospital hasta el momento presente han tenido en cuenta la consulta de dos documentos: el primero, custodiado en los fondos del Archivo del Hospital de la Vera Cruz de Medina de Pomar (AHVC) ${ }^{9}$, que alude a la escritura de las ordenanzas de la institución asistencial, antes referido, en el que se encuentra incluido el catálogo de las obras donadas por el primer conde de Haro al hospital; el segundo, custodiado en los fondos de la BNE, con la signatura: BNE, RES/141, antes mencionado, incluye, en el apartado primero, el inventario de los libros reunidos hasta el 27 de mayo de 1553 por la institución asistencial y, en el apartado segundo, el catálogo de las obras donadas el 14 de agosto de 1455 por el conde al hospital.

Observo, en consecuencia, que el inventario de la colección de libros, contenido en el primer documento, no ha sido objeto de una labor de identificación y glosa de carácter exhaustivo. Sin embargo, los catálogos de las dos dotaciones de obras, contenidos en el segundo documento, cuentan con sus respectivas tareas de análisis.

Por lo que mi objetivo en el presente artículo consiste, por un lado, en la realización de la transcripción del inventario de los libros donados por Pedro Fernández de Velasco a la institución asistencial, incluido en una copia del documento original de las ordenanzas del hospital, contenida en los fondos del $\mathrm{AHVC}^{10}$, y, por otro

${ }^{6}$ GONZÁLEZ CRESPO, E.: Elevación de un linaje nobiliario castellano en la Baja Edad Media: Los Velasco, (Tesis doctoral), Universidad Complutense de Madrid, 1981.

7 LAWRANCE, J. N. H.: «Nueva luz sobre la biblioteca del conde de Haro: Inventario de 1455». El Crotalón. Anuario de Filología Española, 1, (1984), págs. 1073-1111.

8 BNE, RES/141, fol. 1r.

9 Dichos fondos se encuentran depositados, desde 1963, en el Monasterio de Santa Clara de Medina de Pomar. En la indicada fecha tuvo lugar el cese de las actividades asistenciales del hospital. Vid. PORRES FERNÁNDEZ, C. A. de: «El Hospital de la Vera Cruz», en El Monasterio de Santa Clara de Medina de Pomar. Burgos, Fundación y Patronazgo de la Casa de Velasco, 2004, pág. 333. 
lado, en la labor de identificación, comentario y clasificación, de carácter exhaustivo, de dicho inventario.

\section{INVENTARIO DE LOS LIBROS DONADOS POR EL PRIMER CONDE DE HARO AL HOSPITAL DE LA VERA CRUZ DE MEDINA DE POMAR}

\subsection{Consideraciones preliminares}

Se efectuará la transcripción del catálogo de las obras donadas por Pedro Fernández de Velasco al Hospital de la Vera Cruz de Medina de Pomar, contenido en una copia del documento original de las ordenanzas otorgadas el 13 de diciembre de 1455, en Valladolid, por el conde a la institución asistencial. La citada copia se incluye en los fondos documentales del AHVC, los cuales se encuentran custodiados en la actualidad en el Monasterio de Santa Clara de Medina de Pomar ${ }^{11}$. No obstante, tales fondos, hasta el día de la fecha, no se encuentran catalogados, por lo que, como propuesta para el presente artículo, se citará, de la copia, el texto correspondiente al inventario con la signatura siguiente: AHVC, Ordenanzas del Hospital, fols. 17v-18v. Asimismo, la copia no se encuentra datada. Sin embargo, teniendo presente el texto objeto de la transcripción, el libro $n .^{\circ}$ LXXVI reza lo siguiente: «El libro del bezerro, le (sic) ${ }^{12}$ pidió la señora duquesa ${ }^{13}$ en / 14 de diciembre de $1706 />^{14}$, por lo que podemos datarla a partir de la indicada fecha.

La transcripción del catálogo se realizará según las normas indicadas en el Tratado de Paleografía Española de Agustín Millares Carló y José Manuel Ruiz Asencio ${ }^{15}$. Y las obras del mismo, con objeto de facilitar su lectura, se enumerarán según la foliación romana.

\subsection{Transcripción}

Libros en latín, en pergamino /

I. Una bribia /

II. Vi(i)ndo ${ }^{16}$ de Senis /

\footnotetext{
10 Se trata de una copia del documento original, que no ha sido posible localizar.

11 Vid. n. 10.

12 Vid. n. 20.

${ }^{13}$ Ana María Téllez-Girón y Benavides (m. 1717), casada en 1705 con José Fernández de Velasco y Tovar (m. 1713), VIII duque de Frías y XI conde de Haro.

14 AHVC, Ordenanzas del Hospital, fol. 18v.

15 MILLARES CARLO, A. y RUIZ ASENCIO, J. M.: Tratado de Paleografía Española. Tomo II. Madrid, Espasa-Calpe, 1983, págs. IX-XXIII.

16 Dentro de la palabra analizada, se incluye entre paréntesis la sílaba o sílabas consideradas como un añadido inútil del escriba o copista, y que si no hubiera sido advertido por parte del transcriptor puede dar lugar a una interpretación errónea de la mencionada palabra. Vid. MILLARES CARLO, A. y RUIZ ASENCIO, J. M., Op. Cit., pág. XIV.
} 
III. La margarita /

IV. Un libro de las epístolas de San Gerónimo /

V. Otro libro de las epístolas de San Agustín /

VI. Otro libro de vita Christi, sobre la pasión de Nuestro Señor, / en latín /

VII. El libro de vitis patr(i)um, con ciertos milagros de / Nuestra Señora /

VIII. El libro de Ambrosio, de oficiis /

IX. El libro de Tulio, de oficiis /

X. Otro libro de Bernardo, de [E]ugenio ${ }^{17} /$

XI. Otro libro que se llama Elox (?) ${ }^{18} /$

XII. Otro libro que se llama Mazitatorum mediis (sic) ${ }^{19} /$

XIII. Otro libro que se llama Estímulo mamotis (sic) /

XIV. Otro libro que se llama Bernardo [di]ligendo Deum /

$\mathrm{XV}$. El regimiento de los príncipes /

XVI. La corónica del arzobispo don Rodrigo /

XVII. La catomina (sic) /

XVIII. La corónica gerosolimica (sic) /

XIX. El memorial de las birtudes /

XX. Un libro de los milagros de Nuestra Señora /

XXI. Catolicon /

XXII. Un brebiario pequeño, guarnecido / (18r)

XXIII. Otro brebiario guarnecido /

XXIV. Un misal de (sic) /

$\mathrm{XXV}$. Otro misal /

XXVI. Un brebiario de Nuestra Señora /

17 Los corchetes o paréntesis cuadrados se emplean para indicar que las letras o palabras en ellos contenidas no fueron escritas por el amanuense o copista, aunque se considera necesaria su inclusión para la lectura correcta. Vid. MILLARES CARLO, A. y RUIZ ASENCIO, J. M., Op. Cit., pág. XIII.

${ }_{18}$ En el supuesto de alguna lectura dudosa, se indica, a continuación de la versión dada, una interrogación entre paréntesis. Vid. MILLARES CARLO, A. y RUIZ ASENCIO, J. M., Op. Cit., pág. XIII.

${ }_{19}$ En el supuesto de apreciarse una palabra con ortografía anómala, se sigue la norma de indicarla mediante el vocablo «sic», escrito entre paréntesis. Vid. MILLARES CARLO, A. y RUIZ ASENCIO, J. M., Op. Cit., pág. XIII. 
XXVII. Otro salterio de Nuestra Señora, con ciertas oras /

XXVIII. Otro libro de oras pequeño /

XXIX. Otro libro de oraciones, con salmos penitenciales /

XXX. <Otro sa[l]terio de / Nuestra Señora $>^{20}$ /

Libros en latín, de papel /

XXXI. La peregrina /

XXXII. Badem[ec]um /

XXXIII. La glosa de Julio, de oficiis /

XXXIV. Julio, de senectute /

XXXV. Ignocencio (sic), de miseria /

Libros en romance, de pergamino /

XXXVI. La primera parte de los morales de Job /

XXXVII. La segunda de los morales de Job /

XXXVIII. La tercera parte de los morales de Job /

XXXIX. La corónica del rey don Pedro y del rey don Enrrique / y del rey don (?), en un bolumen /

XL. Y (sic) los trabajos de Ércules y el libro de la guerra, / en un bolumen /

XLI. La demanda del Santo Grial /

XLII. La primera década, Titus Lidio (sic) /

XLIII. La segunda década, Titus Lidio (sic) /

XLIV. Séneca /

$\mathrm{XLV}$. El fuero de las leyes /

XLVI. El libro de las tribulaciones y el libro de vita / christiana de Santo [A]gostín, en un volumen /

Libros en romance, de papel /

XLVII. Leomarte, con una escritura que fizo el obispo de / Burgos sobre los asentamientos de los reyes de Castilla / y de Inglaterra en corte romana /

XLVIII. Las flores de los morales de Job /

20 Las letras o palabras escritas por el amanuense o por un copista posterior entre líneas o al margen, con el propósito de subsanar omisiones o errores, son incluidas entre paréntesis angulares. Vid. MILLARES CARLO, A. y RUIZ ASENCIO, J. M., Op. Cit., pág. XIV. 
Las siete partidas /

XLIX. La primera y cuarta partida, en un volumen /

L. La segunda y tercera y setena partida, en un volumen / (18v)

LI. La quinta y sexta partida, en un volumen.

LII. En (sic) Julio Fronti- / -no /

LIII. La comedia y proberbios del marqués de Santilla- / -na y Jul[i]o de Mazica, en un volumen /

LIV. Salustio /

LV. Petrarca, de vita solitari (sic) /

LVI. Luerco (sic), de consolación /

LVII. Ioan Gallens /

LVIII. Ioan Vocacio /

LIX. La corónica abrebiada de los emperadores /

LX. Valerio Máximo /

LXI. Lucano /

LXII. Vita Christi de fray Jermes (sic) Ximenes /

LXIII. Vergel de consolación /

LXIV. La glosa del regimiento de los príncipes y el libro / que fizo mesén (sic) Diego de Valera, en un volumen /

LXV. El libro del li[ce]nciado de Santo [A]gostín /

LXVI. El libro de San Gerónimo /

LXVII. El regimiento de los príncipes, glosado, en que fallece / el tercero libro /

LXVIII. La corónica del rey don Fernando, que ganó a Sebilla, y del / rey don Alonso, su fijo, y del rey don Sancho, su nieto /

LXIX. La corónica del rey don Alonso, padre del rey don / Juan.

LXX. La segunda parte de la corónica del rey don Rodri- / -go, de cómo se perdió la tierra /

LXXI. El libro de los padres /

LXXII. El libro de las tres cre[e]ncias para contra los judíos /

LXXIII. Otro libro que fizo rabí Moysén de Egipto /

LXXIV. Otro libro que ficieron dos sabios judíos / 
LXXV. El libro de los sabios /

LXXVI. El libro del bezerro, le (sic) pidió la señora duquesa ${ }^{21}$ en / 14 de diciembre de 1706 /

LXXVII. El libro del seguro de Otordesillas (sic) /

Libros en francés /

LXXVIII. Árbol de batallas /

LXXIX. El libro de las cuestiones /

LXXX. Las contemplaciones /

3. NOTAS AL INVENTARIO DE LOS LIBROS DONADOS POR EL PRIMER CONDE DE HARO AL HOSPITAL DE LA VERA CRUZ DE MEDINA DE POMAR

\subsection{Consideraciones preliminares}

En el presente apartado, en primer lugar, se indicará, siempre que sea posible, la correspondencia de las obras incluidas en el documento que transcribo con los libros del inventario estudiado por Jeremy Lawrance (el cual se denominará «Inventario») y del catálogo estudiado por Antonio Paz y Meliá y Jeremy Lawrance (el cual se denominará «Catálogo»), contenidos en el documento con la signatura: BNE, RES/141.

En segundo lugar, se identificarán, siempre que sean conocidos, dichos libros con la colección inicial de obras del Hospital de la Vera Cruz de Medina de Pomar, cuyos manuscritos se encuentran custodiados en la actualidad en la BNE.

Y en tercer lugar, se realizará una labor de glosa de los libros identificados.

Las obras del Inventario, con objeto de facilitar su lectura, serán enumeradas según la foliación romana, y las del Catálogo según la foliación arábiga.

\subsection{Notas}

I. «Una bribia /»22:

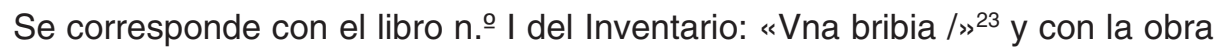
$\mathrm{n}$. 1 del Catálogo: «La Biblia: volumen y regla de la Escritura / Sagrada, escrita de

\footnotetext{
21 Vid. n. 14.

22 AHVC, Ordenanzas del Hospital, fol. 17v.

23 BNE, RES/141, fol. 20r.
} 
mano, en pargamino, con ma- / -nillas de plata y las armas de Velasco /»24. Identificado con el documento con la signatura: BNE, MSS/9200, que contiene un ejemplar, en lengua latina, de la Biblia. Se trata de un códice francés del siglo XIII, en pergamino, iluminado.

II. «Vi(i)ndo de Senis /»25:

Se corresponde con el libro n. $\circ$ II del Inventario: «Vindo de Senis $/ »^{26}$ y con la obra n. 54 del Catálogo: «Tratado del maestro fray Vado de Senas, que / declara y contiene muchas virtudes, por 138 ca- / -pítulos; y al fin, un tratado de los libros de la / Biblia sobre el Viejo y Nuebo Testamento, en 22 / capítulos /»27. Identificado con el documento con la signatura: BNE, MSS/9210, que contiene un ejemplar, en lengua latina, de las Distintiones super Bibliam, escritas por Vindus de Senis, Ordo Fratum Sancti Augustini (OSA). Se trata de un manuscrito del siglo XIII/XIV, en pergamino.

III. «La margarita /»28:

Se corresponde con el libro n. III del Inventario: «La margarita /»29 y con la obra n. 80 del Catálogo: «Otro libro, intitulado Margarita, de fray / Guidón, sacerdote de la yglesia de Ferrara. Trata / de la exposición, con breves declaraciones, de la / Biblia, escrito de mano, en pergamino $/>^{30}$. Identificado con el documento con la signatura: BNE, MSS/9470, que contiene un ejemplar, en lengua latina, copiado por el escriba Juan Escobedo de Salamanca, de la Margarita Bibliae, escrita por Guido de Vicenza, Ordo Praedicatorum. Se trata de un códice del siglo XV, en pergamino.

IV. «Un libro de las epístolas de San Gerónimo /»31:

Se corresponde con el libro n. IV del Inventario: «Vn libro de epístolas de San

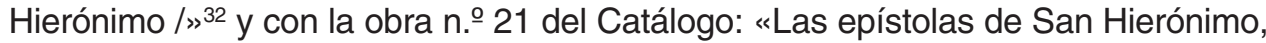
de mano, / en latín, en 122 hojas de pargamino / „33. Identificado con el documento con la signatura: BNE, MSS/12801, que contiene un ejemplar, en lengua latina, de las Epistulae, escritas por San Jerónimo. Se trata de un manuscrito francés del siglo XIII, en pergamino, con miniaturas.

V. «Otro libro de las epístolas de San Agustín /»34:

Se corresponde con el libro $n .^{\circ}$ V del Inventario: «Otro libro de epístolas de Sant Agostín / ${ }^{35}$ y con la obra n.ำ 73 del Catálogo: «Epístolas de San Agustín,

24 BNE, RES/141, fol. 1v.

25 AHVC, Ordenanzas del Hospital, fol. 17v.

26 BNE, RES/141, fol. 20r.

BNE, RES/141, fol. 5r.

8 AHVC, Ordenanzas del Hospital, fol. 17v.

BNE, RES/141, fol. 20r.

BNE, RES/141, fol. 8v.

AHVC, Ordenanzas del Hospital, fol. 17v.

BNE, RES/141, fol. 20r.

BNE, RES/141, fol. 3r.

AHVC, Ordenanzas del Hospital, fol. 17v.

BNE, RES/141, fol. 20r. 
escrito en perga- / -mino, de mano, en ${ }^{36}$ latín; contiene diver- / -sas materias $/>^{37}$. Identificado con el documento con la signatura: BNE, MSS/12835, que contiene un ejemplar, en lengua latina, de las Epistulae, escritas por San Agustín. Se trata de un códice francés del siglo XIII/XIV, en pergamino, con miniaturas.

VI. «Otro libro de vita Christi, sobre la pasión de Nuestro Señor, / en latín /»38:

Se corresponde con el libro n. VI del Inventario: «Otro libro vita Christi, sobre la pasión de / Nuestro Señor, en latín /» ${ }^{39}$ y con la obra n. 20 del Catálogo: «Las meditaciones de la pasión de Nuestro / Señor, echas por San Buenaventura, de mano, / (3r) en pargamino, en lengua latina $/{ }^{40}$. Identificado con el documento con la signatura: BNE, MSS/12797, que contiene un ejemplar, en lengua latina, de las Meditationes vitae Christi, atribuidas a San Buenaventura. Se trata de un manuscrito del siglo XIV, en pergamino.

VII. «El libro de vitis patr(i)um, con ciertos milagros de / Nuestra Señora /»41:

Se corresponde con el libro $n .^{\circ}$ VII del Inventario: «El libro de vitis patrum, con ciertos mila- / -gros de Nuestra Señora /» ${ }^{42}$ y con la obra n. 925 del Catálogo: «Las exhortaciones de los Santos Padres / para provecho de la perfección de los religiosos, / escrito de mano, en pargamino, en lengua lati- / -na, en 82 hojas /»43. Identificado con el documento con la signatura: BNE, MSS/9289, que contiene un ejemplar, en lengua latina, de las Ad hortationes sanctorum patrum ad profectum perfectionis monachorum, cuyo autor es anónimo. Se trata de un códice del siglo $\mathrm{XIV}$, en pergamino.

VIII. «El libro de Ambrosio, de oficiis /»44:

Se corresponde con el libro $n .{ }^{\circ}$ VIII del Inventario: «El libro de Ambrosio, de oficiis / ${ }^{45}$ y con la obra n. ${ }^{\circ} 59$ del Catálogo: «Tratado de San Ambrosio, de oficiis, en / lengua latina, en tres libros y al fin una apos- / -tilla, de talentis y sobre los cánticos, escrito en / pargamino / $/ 46$. Identificado con el documento con la signatura: BNE, MSS/9482, que contiene un ejemplar, en lengua latina, del De officiis ministrorum, escrito por San Ambrosio. Se trata de un manuscrito boloñés del siglo XV, en pergamino.

\footnotetext{
Tachadura de la palabra «romance».

BNE, RES/141, fol. 7v.

AHVC, Ordenanzas del Hospital, fol. 17v.

BNE, RES $/ 141$, fol. 20r.

BNE, RES/141, fols. 2v-3r.

AHVC, Ordenanzas del Hospital, fol. 17v.

BNE, RES/141, fol. 20r.

BNE, RES/141, fol. 3r.

4 AHVC, Ordenanzas del Hospital, fol. 17v.

45 BNE, RES/141, fol. 20r.

6 BNE, RES/141, fol. $6 r$.
} 
IX. «El libro de Tulio, de oficiis /»47:

No presenta correspondencia con libro alguno del Inventario y se corresponde con la obra $n .^{\circ} 92$ del Catálogo: «Tullio, de oficiis, escrito de mano, en parga- / mino / ${ }^{48}$. Identificado con el documento con la signatura: BNE, MSS/12839, que contiene un ejemplar, en lengua latina, copiado en 1417 por Matteo de' Griffoni, del De officiis, escrito por Marco Tulio Cicerón. Se trata de un códice boloñés, en pergamino, ricamente miniado.

X. «Otro libro de Bernardo, de [E]ugenio /»49:

Se corresponde con el libro $\mathrm{n} . \stackrel{\circ}{ }$ IX del Inventario: «Otro libro de Bernarldo, de Eugenio $/ \gg^{50}$ y con la obra $n .{ }^{\circ} 30$ del Catálogo: «Tratado de San Bernardo, sobre amar a Dios $/>^{51}$. Se encuentra sin identificar.

XI. «Otro libro que se llama Elox (?) /»52:

Se corresponde con el libro $\mathrm{n} .^{\circ} \mathrm{X}$ del Inventario: «Otro libro que se llama Eulox[ium] / $»^{53}$ y con la obra $n .^{\circ} 55$ del Catálogo: «Libro escrito de mano sobre la guerra de / Babilonia y Hierusalem, en 77 hojas; y al fin / (5v) de él, la historia de San Athanasio, cardenal ale- / -xandrino, en el año 1061. Contiene el origen / de San Athanasio y Arrio, ambos de Ytalia, y / su familiaridad en los estudios por 24 años en / Babilonia y después por todas las vniversidades, / buscando con quién disputar, hasta que se apartaron / con promesa de no se contradecir en disputas si no / fuese en artículos de la fe. Escrivió San Atha- / -nasio el símbolo Quicumque vult y pidió a Nuestro / Señor para los cofrades o familiares de Nuestra / Señora de Valvanera, merced de bien morir $/>^{54}$. Identificado con el documento con la signatura: BNE, MSS/9456, que contiene un ejemplar, en lengua latina, del Liber vocatus Heulogium compositus super Psalmum 12 usquequo domine, escrito en el siglo XV por Joan Armengol, obispo de Barcelona, y con el documento con la signatura: BNE, MSS/9467, que contiene un ejemplar, en lengua latina, de la Historia Sancti Athanasi, escrita en el siglo XIV por el papa Inocencio III.

XII. «Otro libro que se llama Mazitatorum mediis (sic) /» $\$ 5$ :

Se corresponde con el libro $n .{ }^{\circ} \mathrm{XI}$ del Inventario: «Otro libro que se llama Citatorium medis (sic) /»56 y con la obra n. ${ }^{5} 56$ del Catálogo: «Tratado de Rodrigo Díez, obispo de Valen- / -cia, de cómo se ha de exercitar el ánimo para / con Dios,

\footnotetext{
47 AHVC, Ordenanzas del Hospital, fol. 17v.

48 BNE, RES/141, fol. 10v.

49 AHVC, Ordenanzas del Hospital, fol. 17v.

50 BNE, RES/141, fol. 20r.

BNE, RES/141, fol. 3v.

AHVC, Ordenanzas del Hospital, fol. 17v.

BNE, RES/141, fol. 20r.

BNE, RES/141, fols. 5r-5v.

AHVC, Ordenanzas del Hospital, fol. 17v.

BNE, RES/141, fol. 20r.
} 
escrito de mano, en pergamino / $/>^{57}$. Identificado con el documento con la signatura: BNE, MSS/9265, que contiene un ejemplar, en lengua latina, del Excitatorium mentis ad Deum, escrito por fray Bernat Oliver de Valencia, OSA. Su destinatario: Rodrigo Díez, obispo de Valencia. Se trata de un manuscrito del siglo XV, en pergamino.

XIII. «Otro libro que se llama Estímulo mamotis (sic) / $»^{58}$ :

Se corresponde con el libro n. XII del Inventario: «Otro libro que se llama Stimulo mamoris (sic) / $/{ }^{59}$ y con la obra n. -28 del Catálogo: «Tratado pequeño del Estímulo amoris in / Christum y, a lo último, contiene los gozos de Nuestra / Señora» ${ }^{60}$. Identificado con el documento con la signatura: BNE, MSS/9536, que contiene un ejemplar, en lengua latina, del Stimulus amoris, atribuido a San Buenaventura. Se trata de un códice del siglo XIV/XV, en pergamino.

XIV. "Otro libro que se llama Bernardo [di]ligendo Deum /»61:

Se corresponde con el libro $\mathrm{n} .-\mathrm{X}$ XIII del Inventario: «Otro libro que se llama Bernaldo diligendo / Deum / (20v) »"62 y con la obra n. 30 del Catálogo: «Tratado de San Bernardo, sobre amar a Dios $/{ }^{663}$. Se encuentra sin identificar.

$X V$. «El regimiento de los príncipes /»64:

Se corresponde con el libro n.․ XIV del Inventario: «El regimiento de los príncipes $/ \gg^{65}$ y con la obra n. 0109 del Catálogo: «Fray Egidio Romano, del orden de San / Agustín, que trata del regimiento de los prín- / -cipes, escrito de mano, en latín, en 150 hojas, illu- / -minado y con manillas de plata y oro / / ${ }^{66}$. Identificado con el documento con la signatura: BNE, MSS/9236, que contiene un ejemplar, en lengua latina, del De regimine principum, escrito por Egidio Romano, OSA. Se trata de un manuscrito francés del siglo XIV, en pergamino, ricamente miniado.

XVI. «La corónica del arzobispo don Rodrigo /»67:

Se corresponde con el libro n. XV del Inventario: «La corónica del arzovispo don Rodrigo / $/{ }^{68}$ y con la obra n. .145 del Catálogo: «Tratado del arzovispo don Rodrigo, de la chró- / -nica de España, donde trata de la historia gó- / -thica y otras

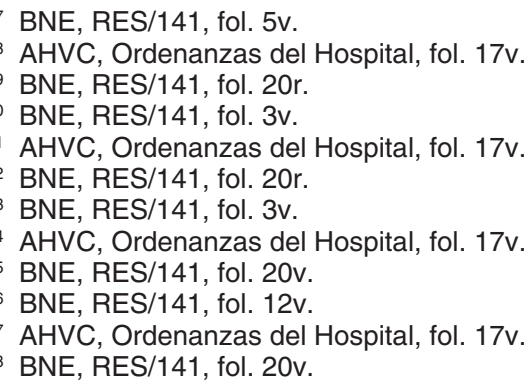


muy antiguas, escrito de mano, / en latín, en 108 hojas de pergamino /»69. Se encuentra sin identificar.

XVII. «La catomina (sic) / $\gg 70$ :

Se corresponde con el libro n. ${ }^{\circ} \mathrm{XVI}$ del Inventario: «La catonina (sic) /» 71 y con la obra n. 149 del Catálogo: «Vna carta sin autor, dirigida ad in- / -ditum (sic) et magnificum virum dominum Pe- / -trum Fernandi de Velasco, comitem de / (17v) de (sic) Haro et dominum antiquae domus de / Salas, serenisimi atque invictisimi domini nostri re- / -gis archicamerarium; contiene 12 capítulos / e acauada la carta ay dos libros de versos / en su loa, todo escrito en pargamino, de mano, / illuminado y con las armas de Velasco, forra- / -do en raso azul y con manillas de plata sobre- / -dorada / $/{ }^{72}$. Identificado con el documento con la signatura: BNE, MSS/9208, que contiene un ejemplar, en lengua latina, de la Epistula directa ad inclitum et magnificum virum dominum Petrum Fernandi de Velasco, Comitem de Haro (fols. 1r-26r), escrita por Alonso de Cartagena (1384-1456), obispo de Burgos, y un ejemplar, en lengua latina, del Cathoniana confectio (fols. 27r-78r), escrito por Dionisio Catón. Se trata de un códice flamenco-castellano de mediados del siglo $\mathrm{XV}$, en pergamino, iluminado.

XVIII. «La corónica gerosolimica (sic) /»73:

Se corresponde con el libro n. XVII del Inventario: «La corónica gerosolimitana /» ${ }^{74}$ y con la obra n. ${ }^{1} 123$ del Catálogo: «Chrónica hierosolemitana, de mano, en 45 ho- / -jas de pargamino, por el maestro Thadeo, en la ciudad / de Mesana, año del Señor de 1291, a 5 de dici- / -embre; contiene muchas exclamaciones a Dios / y al Papa y a los reyes christianos, y planctos del / reyno de Hierusalem y otras muchas cosas, / en diversos capítulos / $/{ }^{75}$. Identificado con el documento con la signatura: BNE, MSS/9201, que contiene un ejemplar, en lengua latina, de La Coronica Hierosolimitana, escrito por Gulielmus, arzobispo de Tiro, y un ejemplar, en lengua latina, del De desolatione et conclamatione civitatis acconensis et totius terre sancte, escrito por Tadeus Neapolitanus. Se trata de un manuscrito francés del siglo XIII, en pergamino.

XIX. «El memorial de las birtudes /» 76 :

Se corresponde con el libro $\mathrm{n} .^{\circ} \mathrm{XVIII}$ del Inventario: «El memorial de las virtu-

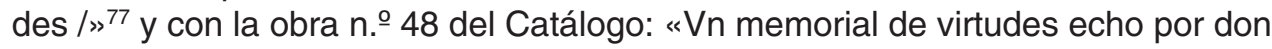

\footnotetext{
69 BNE, RES/141, fol. 16v.

AHVC, Ordenanzas del Hospital, fol. 17v.

BNE, RES/141, fol. 20v.

BNE, RES/141, fols. $17 \mathrm{r}-17 \mathrm{v}$.

AHVC, Ordenanzas del Hospital, fol. 17v.

BNE, RES/141, fol. 20v.

BNE, RES/141, fol. 14r.

AHVC, Ordenanzas del Hospital, fol. 17v.

BNE, RES/141, fol. 20v.
} 
/ (5r) Alonso de Santa María, doctor en leyes / y deán de Santiago y de Segovia, dirigido al / príncipe Duarto, ynfante de Portugal; y ay / otro libro de por sí del mismo autor y del mismo / título que deve estar duplicado /»78. Identificado con los documentos con las signaturas siguientes: BNE, MSS/9178 y BNE, MSS/9212, que contienen, respectivamente, un ejemplar, en lengua latina, del Memoriale virtutum, escrito en el siglo XV por Alonso de Cartagena, obispo de Burgos.

XX. «Un libro de los milagros de Nuestra Señora /» 79 :

Se corresponde con el libro $n .{ }^{\circ} \mathrm{XIX}$ del Inventario: «Vn libro de los milagros de

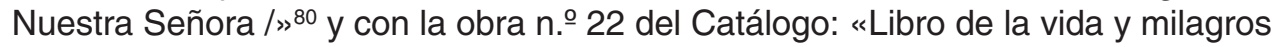
de Nuestra Señora, / con muchas loas suyas, escrito en latín, de / mano, en pergamino /»81. Identificado con el documento con la signatura: BNE, MSS/9503, que contiene un ejemplar, en lengua latina, del Liber Jhesu et Mariae, escrito por fray Juan Gil de Zamora, Ordo Fratrum Minorum (OFM). Se trata de un códice del siglo XIV, en pergamino.

XXI. «Catolicon /»82:

Se corresponde con el libro n. ${ }^{\circ}$ XX del Inventario: «Catholicon /» ${ }^{83}$ y con la obra n. 9 del Catálogo: «Libro intitulado Catholicon Joannis Ja- / -nuensis, de la Orden de los Predicadores, escrito / en pargamino, en lengua latina, sobre prosodia / y sus partes $/ \gg 84$. Se encuentra sin identificar.

XXII. «Un brebiario pequeño, guarnecido / (18r)»85:

Se corresponde con el libro n. ${ }^{\mathrm{O} X \mathrm{XI}}$ del Inventario: «Vn briviario pequeño, guarnecido / $\gg{ }^{86}$ y con la obra $n .{ }^{\circ} 3$ del Catálogo: «Vn breviario romano antiguo, escrito / de mano, en pargamino, con algunas oracio- / -nes de devoción al principio /»87. Identificado con el documento con la signatura: BNE, MSS/9082, que contiene un ejemplar, en lengua latina, del Breviarium secundum consuetudinem curiae romanae. Se trata de un manuscrito italiano del siglo XIV/XV, en pergamino.

XXIII. «Otro brebiario guarnecido /»88:

Se corresponde con el libro $\mathrm{n} .^{\circ} \mathrm{XXII}$ del Inventario: «Otro briviario guarnecido / ${ }^{89} \mathrm{y}$, de una manera tentativa, con la obra $\mathrm{n} . \stackrel{0}{5}$ del Catálogo: «Libro antiguo que

\footnotetext{
78 BNE, RES/141, fols. 4v-5r.

79 AHVC, Ordenanzas del Hospital, fol. 17v.

30 BNE, RES/141, fol. 20v.

BNE, RES/141, fol. 3r.

2 AHVC, Ordenanzas del Hospital, fol. 17v.

33 BNE, RES/141, fol. 20v.

BNE, RES/141, fol. $2 r$.

AHVC, Ordenanzas del Hospital, fol. 17v.

BNE, RES/141, fol. 20v.

BNE, RES/141, fol. 1V.

AHVC, Ordenanzas del Hospital, fol. 18r.

BNE, RES/141, fol. 20v.
} 
contiene el oficio de / la septuagéssima, sexagésima, quadragé- / (2r) -ssima y quinquagésima $/ \gg^{90}$. Se encuentra sin identificar.

XXIV. «Un misal de (sic) /»91:

Se corresponde con el libro $n .^{\circ}$ XXIII del Inventario: «Un misal /» ${ }^{92}$ y, como tentativa, con la obra $n . \stackrel{\circ}{27}$ del Catálogo: «Vn misal, de molde, en pergamino, en 361 ojas / (3v)»93, considerando que la alusión «de molde» es equívoca. De tal manera, se identifica con el documento con la signatura: BNE, MSS/9469, que contiene un ejemplar, en lengua latina, del Missale Franciscanum consuetudinis monasterii sancte Clarae de Astudillo. Se trata de un códice castellano del siglo XIV, en pergamino.

XXV. «Otro misal /»94:

Se corresponde con el libro $n .{ }^{\circ}$ XXIV del Inventario: «Otro misal /»95 y con la obra n. 49 del Catálogo: «Un misal, con sus oraciones, escrito de / mano /»96. Identificado con el documento con la signatura: BNE, MSS/9538, que contiene un ejemplar, en lengua latina, del Missale Romanum. Se trata de un manuscrito italiano de mediados del siglo XIV, en pergamino.

XXVI. «Un brebiario de Nuestra Señora /»97:

Se corresponde con el libro $n .^{\circ}$ XXV del Inventario: «Un breviario de Nuestra Señora /»98 y con la obra $n .^{\circ} 4$ del Catálogo: «Vn breviario de Nuestra Señora, en que / se contienen sus gozos / $/{ }^{99}$. Identificado con el documento con la signatura: BNE, MSS/9533, que contiene un ejemplar, en lengua latina, del Breviarium Beatae Mariae Virginis. Se trata de un códice castellano del siglo XV, en pergamino.

XXVII. «Otro salterio de Nuestra Señora, con ciertas oras /»100:

Se corresponde con el libro $\mathrm{n} .^{\circ} \mathrm{XXVI}$ del Inventario: «Otro salterio de Nuestra Señora, con / ciertas oras / $/{ }^{101} \mathrm{y}$, de una manera tentativa, con la obra $\mathrm{n} . \stackrel{0}{6 \text { del }}$ Catálogo: «Otro libro del psalterio de Nuestra Señora /»102. De dicha manera, se identifica con el documento con la signatura: BNE, MSS/9541, que contiene un ejemplar, en lengua latina, del Psalterium Beatae Mariae Virginis. Se trata de un

\footnotetext{
BNE, RES/141, fols. 1v-2r.

AHVC, Ordenanzas del Hospital, 18r.

BNE, RES/141, fol. 20v.

BNE, RES/141, fol. 3r.

AHVC, Ordenanzas del Hospital, fol. 18r.

BNE, RES/141, fol. 20v.

BNE, RES/141, fol. 5r.

AHVC, Ordenanzas del Hospital, fol. 18r.

BNE, RES/141, fol. 20v.

BNE, RES/141, fol. 1v.

100 AHVC, Ordenanzas del Hospital, fol. 18r.

101 BNE, RES/141, fol. 20v.

102 BNE, RES/141, fol. 2 r.
} 
manuscrito castellano del siglo XV, en pergamino, que incluye un libro de horas mariano.

XXVIII. «Otro libro de oras pequeño /» ${ }^{103:}$

Se corresponde con el libro n.. XXVII del Inventario: «Otro libro de oras pequeño / $>^{104}$ y no presenta correspondencia con obra alguna del Catálogo. Se encuentra sin identificar.

XXIX. "Otro libro de oraciones, con salmos penitenciales /» 105 :

Se corresponde con el libro n. XXVIII del Inventario: "Otro libro de oraciones, con psalmos peniten- / -ciales / / ${ }^{106}$ y con la obra n. 084 del Catálogo: «Libro de diversas oraciones, donde están / los psalmos penitenciales y los gozos de Nu- / -estra Señora, con sus versos y oraciones de / cada gozo, escrito de mano, en pargamino, en for- / -ma de misal / $>107$. Identificado, de una manera disyuntiva, con el documento con la signatura: BNE, MSS/9543, o bien, con el documento con la signatura: BNE, MSS/9540. El primer documento contiene un ejemplar, en lengua latina, de un códice castellano del siglo XV, en pergamino, que incluye un devocionario iluminado con salmos. El segundo documento contiene un ejemplar, en lengua latina, de un manuscrito castellano del siglo XIV/XV, en pergamino, que incluye prosas y gaudia marianos.

XXX. «<Otro sa[l]terio de / Nuestra Señora $>$ / $\gg 108$ :

Se corresponde con el libro n. ${ }^{\circ}$ XXIX del Inventario: «Otro salterio de Nuestra Señora /» 109 y, como tentativa, con la obra $n . .6$ del Catálogo: "Otro libro del psalterio de Nuestra Señora / $/{ }^{110}$. De tal manera, se identifica con el documento con la signatura: BNE, MSS/9541, que contiene un ejemplar, en lengua latina, del Psalterium Beatae Mariae Virginis. Se trata de un códice castellano del siglo XV, en pergamino, que incluye un libro de horas mariano.

XXXI. «La peregrina /»111:

Se corresponde con el libro n.. XXX del Inventario: «La peregrina /»112 y con la obra n. 138 del Catálogo: «La peregrina, en latín, sobre las siete partidas /»113. Identificado con el documento con la signatura: BNE, MSS/12687, que contiene un ejemplar, en lengua latina, de la Peregrina, cuya redacción se atribuye a Gonzalo

\footnotetext{
103 AHVC, Ordenanzas del Hospital, fol. 18r.

04 BNE, RES/141, fol. 20v.

05 AHVC, Ordenanzas del Hospital, fol. 18r.

106 BNE, RES/141, fol. 20v.

7 BNE, RES/141, fol. 9r.

8 AHVC, Ordenanzas del Hospital, fol. 18r.

9 BNE, RES/141, fol. 20v.

BNE, RES/141, fol. 2r.

AHVC, Ordenanzas del Hospital, fol. 18r.

BNE, RES/141, fol. 20v.

BNE, RES/141, fol. 15v.
} 
González de Bustamante. Se trata de un manuscrito del siglo XV, en papel, que incluye un glosario enciclopédico y un comentario de las Siete Partidas.

XXXII. «Badem[ec]um /»114:

Se corresponde con el libro $n .^{\circ}$ XXXI del Inventario: «Bademecum / (21r)»115 y con la obra $n .^{\circ} 35$ del Catálogo: «Vn libro intitulado Vademecum, de dichos / de santos y otras sentencias; y el (sic) un capítulo con- / -tiene la promesa y juramento que hizo la bea- / -titud de Calixto 3.ำ siendo elegido de procurar / de recobrar a Constantinopla, aunque fuere a / riesgo de su propia sangre; escrito de mano, en / (4r) pargamino /»116. Identificado con el documento con la signatura: BNE, MSS/9522, que contiene un ejemplar, en lengua latina y castellana, del Vademecum. Se trata de un códice del siglo $\mathrm{XV}$, en vitela, de asunto religioso y secular.

XXXIII. «La glosa de Julio, de oficiis /»117:

Se corresponde con el libro $n .^{\circ}$ XXXII del Inventario: «La glosa de Julio, de of-

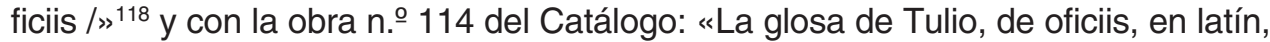
sin / autor ni tiempo /»119. Identificado con el documento con la signatura: BNE, MSS/9225, que contiene un ejemplar, en lengua latina, del Commentarius in M.T. Ciceronis De officiis. Se trata de un manuscrito del siglo XV, en papel.

XXXIV. «Julio, de senectute /»120:

Se corresponde con el libro $n .^{\circ}$ XXXIII del Inventario: «Tullio, de senetute (sic)

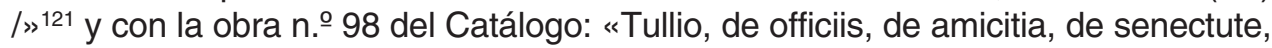
/ (11v) escrito de mano, en pergamino /»122. Identificado con el documento con la signatura: BNE, MSS/9502, que contiene un ejemplar, en lengua latina, del De officiis, de amicitia, de senectute, de paradoxis, escrito por Marco Tulio Cicerón. Se trata de un códice florentino del siglo XV, en papel.

XXXV. «Ignocencio (sic), de miseria /»123:

Se corresponde con el libro $n .{ }^{\circ}$ XXXIV del Inventario: «Inocencio, de miseria /»124 y con la obra $n$. o 79 del Catálogo: «Ynnocencio, sobre la flaqueza de la vida hu- / -mana; trata de la miseria del hombre y de / sus vicios e infortunios, y al fin hace un capítulo / de la castidad y de que la memoria de la muer- / -te es causa de seys bienes en el hombre; está / escrito en mano, en latín / \$125. Identificado con el

\footnotetext{
114 AHVC, Ordenanzas del Hospital, fol. 18r.

15 BNE, RES/141, fol. 20v.

BNE, RES/141, fols. 3v-4r.

AHVC, Ordenanzas del Hospital, fol. 18r.

8 BNE, RES/141, fol. 21r.

BNE, RES/141, fol. 13r.

AHVC, Ordenanzas del Hospital, fol. 18r.

BNE, RES $/ 141$, fol. $21 r$.

BNE, RES/141, fols. $11 \mathrm{r}-11 \mathrm{v}$.

123 AHVC, Ordenanzas del Hospital, fol. 18r.

124 BNE, RES/141, fol. 21r.

125 BNE, RES/141, fol. 8v.
} 
documento con la signatura: BNE, MSS/9481, que contiene un ejemplar, en lengua latina, del De contemptu mundi, escrito por el papa Inocencio III. Se trata de un manuscrito del siglo $X V$, en papel.

XXXVI. «La primera parte de los morales de Job /»126:

Se corresponde con el libro n. ${ }^{\circ}$ XXV del Inventario: «La primera parte de los morales de Job /» ${ }^{127}$ y con la obra n. ${ }^{14}$ del Catálogo: «Los morales de San Gregorio, de mano, en / pargamino; y comienzan de la exposición del / libro de Job, en 76 ojas /»128. Identificado con el documento con la signatura: BNE, MSS/12734, que contiene un ejemplar, traducido en lengua castellana por Pero López de Ayala, del primer tomo de los Morales de S. Gregorio. Se trata de un códice del siglo $\mathrm{XV}$, en pergamino.

XXXVII. «La segunda de los morales de Job /»129:

Se corresponde con el libro $n .{ }^{\circ} \mathrm{XXXVI}$ del Inventario: «La segunda de los morales de Job /» ${ }^{130}$ y con la obra n. 16 del Catálogo: «Los morales de San Gregorio, sobre el pri- / -mer libro de la segunda parte de la explana- / -ción del libro de Job /»131. Identificado con el documento con la signatura: BNE, MSS/12735, que contiene un ejemplar, traducido en lengua castellana por Pero López de Ayala, del segundo tomo de los Morales de S. Gregorio. Se trata de un manuscrito del siglo XV, en pergamino.

XXXVIII. «La tercera parte de los morales de Job /»132:

Se corresponde con el libro $n .^{\circ}$ XXXVII del Inventario: «La tercera parte de los morales de Job /» ${ }^{133}$ y con la obra n. ${ }^{17}$ del Catálogo: «Los morales de San Gregorio, sobre el pri- / -mer libro de la tercera parte, escrito de mano /»134. Identificado con el documento con la signatura: BNE, MSS/12736, que contiene un ejemplar, traducido en lengua castellana por Pero López de Ayala, del tercer tomo de los Morales de S. Gregorio. Se trata de un códice del siglo XV, en pergamino.

XXXIX. «La corónica del rey don Pedro y del rey don Enrrique / y del rey don (?), en un bolumen / $\gg$ 135:

Se corresponde con el libro $n . \stackrel{\circ}{ }$ XXXVIII del Inventario: «La corónica del rey don Pedro e del rey don / Enrrique e del rey don Juan, todos en un volu- / -men /» ${ }^{136}$,

\footnotetext{
AHVC, Ordenanzas del Hospital, fol. 18r.

BNE, RES/141, fol. 21r.

BNE, RES/141, fol. 2v.

AHVC, Ordenanzas del Hospital, fol. 18r.

30 BNE, RES/141, fol. 21r.

BNE, RES/141, fol. 2v.

AHVC, Ordenanzas del Hospital, fol. 18r.

BNE, RES/141, fol. 21r.

BNE, RES $/ 141$, fol. 2v.

AHVC, Ordenanzas del Hospital, fol. 18r.

136 BNE, RES/141, fol. 21r.
} 
aunque no tiene correspondencia con obra alguna del Catálogo. Se encuentra sin identificar.

$X L$. «Y (sic) los trabajos de Ércules y el libro de la guerra, / en un bolumen /»137:

Se corresponde con el libro n. ${ }^{\circ}$ XXXIX del Inventario: «Los travajos de Hér-

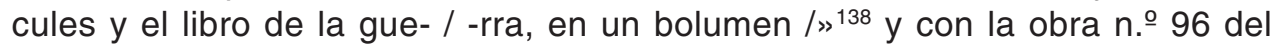
Catálogo: «Libro de los trabajos de Hércules, en 16 / (11r) capítulos; y al fin, el orden que se ha de tener / en los exércitos y batallas, en 36 reglas o ca- / -pítulos / $>139$. Identificado, de una manera tentativa, con el documento con la signatura: BNE, MSS/6526, que contiene un ejemplar, en lengua castellana, de Los trabajos de Hércules, escritos por Enrique de Villena, y un ejemplar, cuya traducción en lengua castellana se atribuye a Enrique de Villena, del De re militari, escrito por Flavio Vegecio Renato. Se trata de un manuscrito del siglo XV, en pergamino.

XLI. «La demanda del Santo Grial /»140:

Se corresponde con el libro $n .{ }^{\circ} \mathrm{XL}$ del Inventario: «La demanda del Santo Grial / $/{ }^{141}$, aunque no tiene correspondencia con obra alguna del Catálogo. Se encuentra sin identificar.

XLII. «La primera década, Titus Lidio (sic) /»142:

Se corresponde con el libro $\mathrm{n} .^{\circ} \mathrm{XLI}$ del Inventario: «La primera década de Ti-

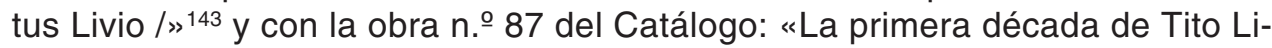
vio, en / (9v) diez libros, en pargamino, traducido de latín / en romance por maestre Pedro de Berceur, / monge de San Hilario, en París, por mandado / del señor rey don Juan de Francia. Está es- / -crito de mano y al fin de él dice: 'Este libro y / chrónica se escrivió en la villa de Haro, lugar / del muy alto príncipe señor don Pedro Fernán- / -dez de Velasco, conde de Haro, en el año del Señor / de 1433 años, a servicio del Señor Dios y del / dicho señor conde; el qual fue escrito por su / mandado y lo escrivió Martín Sánchez / Turcio, escrivano, vecino de dicha villa de / Haro, vasallo y servidor del dicho señor conde. / Laudetur Deus' /»144. Identificado con el documento con la signatura: BNE, MSS/12732, que contiene un ejemplar, traducido en lengua castellana por Pero López de Ayala y copiado en 1433 por Martín Sánchez de Tricio, escriba del primer conde de Haro, de la Primera Década de Tito Livio. Se trata de un códice, en pergamino.

\footnotetext{
137 AHVC, Ordenanzas del Hospital, fol. 18r.

8 BNE, RES/141, fol. 21r.

BNE, RES/141, fols. 10v-11r.

AHVC, Ordenanzas del Hospital, fol. 18r.

BNE, RES/141, fol. 21r.

42 AHVC, Ordenanzas del Hospital, fol. 18r.

143 BNE, RES/141, fol. 21r.

144 BNE, RES/141, fols. 9r-9v.
} 
XLIII. «La segunda década, Titus Lidio (sic) /»145:

Se corresponde con el libro n. ${ }^{\circ}$ XLII del Inventario: «La segunda década de Titus Lidio (sic) / ${ }^{146}$ y con la obra n. 88 del Catálogo: «Segunda década, de diez libros, de Tito / Livio, sobre las historias romanas; trata de / contar la muy noble y grande guerra y ba- / -tallas que hubo entre Roma y Carthago, si- / -endo emperador y governador Hannibal; / está escrita en parcamino (sic) y al fin dice: / 'Aquí se acava el deceno libro de la segunda / (10r) década de Tito Livio, de las batallas que fue- / -ron entre Roma y Carthago' / „147. Identificado con el documento con la signatura: BNE, MSS/12677, que contiene un ejemplar, traducido en lengua castellana por Pero López de Ayala, de la Segunda Década de Tito Livio. Se trata de un manuscrito del siglo XV, en pergamino.

XLIV. «Séneca /» ${ }^{148}$ :

Se corresponde con el libro n. ํ XLIII del Inventario: «Séneca /»149 y con la obra n. 69 del Catálogo: «Séneca, de la providencia de Dios, tra- / -ducido de latín en romance por mandado del / señor rey don Juan el Segundo, en ocho libros: / dos de providencia y dos de clemencia y de / la vida bienaventurada, de las siete artes / liverales y de amonestaciones de Séneca con- / -tra las adversidades de la Fortuna. Está escri- / -to de mano, en 132 hojas, sin otras addicio- / -nes / / 150 . Identificado con el documento con la signatura: BNE, MSS/9180, que contiene un ejemplar, traducido en lengua castellana por Alonso de Cartagena, obispo de Burgos, de los Diálogos, escritos por Lucio Anneo Séneca. Se trata de un códice del siglo XV, en pergamino.

XLV. «El fuero de las leyes /»151:

Se corresponde con el libro n. ${ }^{\circ}$ XLIV del Inventario: «El fuero de las leyes /»152

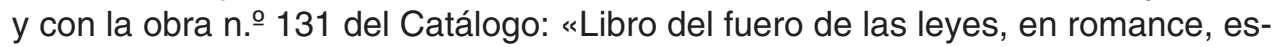
crito de / mano, en pargamino, y del ordenamiento real y / tabla de las leyes de las siete partidas / $/{ }^{153}$. Identificado con el documento con la signatura: BNE, MSS/9199, que contiene un ejemplar, en lengua castellana, del Ordenamiento de Alcalá, y un ejemplar, en lengua castellana, del Fuero Viejo de Castilla. Se trata de un manuscrito del siglo XIV, en pergamino.

XLVI. «El libro de las tribulaciones y el libro de vita / christiana de Santo [A]gostín, en un volumen /»154:

Se corresponde con el libro $n .{ }^{\circ}$ XLV del Inventario: «El libro de las tribulaciones e el libro de / vita christiana de Sant Agostín, en un volumen /»155, aunque no presenta correspondencia con obra alguna del Catálogo. Se encuentra sin identificar.

\footnotetext{
145 AHVC, Ordenanzas del Hospital, fol. 18r.

6 BNE, RES/141, fol. 21r.

BNE, RES/141, fols. 9v-10r.

AHVC, Ordenanzas del Hospital, fol. 18r.

BNE, RES/141, fol. 21r.

BNE, RES $/ 141$, fol. 7r.

AHVC, Ordenanzas del Hospital, fol. 18r.

BNE, RES/141, fol. 21r.

BNE, RES/141, fol. 15r

4 AHVC, Ordenanzas del Hospital, fol. 18r.
} 
XLVII. «Leomarte, con una escritura que fizo el obispo de / Burgos sobre los asentamientos de los reyes de Castilla / y de Inglaterra en corte romana /» 156 :

Se corresponde con el libro n. ${ }^{-}$XLVI del Inventario: «Leomarte, con una escritura que fizo el / (21v) obispo de Burgos sobre los asentamien- / -tos de los reyes de Castilla e de Ynglaterra / de (sic) corte romana / $\gg 157$ y con la obra n. 0152 del Catálogo: «Otro libro que prueva por cinco conclusio- / -nes las grandezas y antigüedades de los re- / -yes de Castilla y Ynglaterra y las razones / porque los reyes de Castilla son preferidos / a los de Ynglaterra, con sus respuestas; y en / la segunda parte trata cómo fue poblada Tro- / -ya en tiempo de Josué, caudillo del pueblo de / Ysrrael, a 1707 años del Dilubio; comenzola / Dárdano y llamola Dardania, de su nom- / -bre; y cómo y por quién fue quatro veces des- / -truyda; comienza por capítulos de Noé / y del daño que le hicieron las vbas de una / (18v) parra, y va discurriendo por capítulos de / quién fue el primer conquistador del mundo / y del nacimiento y echos de Hércules, de / Aquiles y de Paris y de sus muertes y llantos, / y otras muchas historias; todo sin autor / ni año / $>158$. Identificado, como tentativa, con el documento con la signatura: BNE, MSS/9256, que contiene un ejemplar, en lengua castellana, de la Suma de Historia Troyana, escrita en el siglo XIV por Leomarte, y con el documento con la signatura: BNE, MSS/6404, que contiene un ejemplar, en lengua castellana, de la Proposición contra los ingleses, escrita en el siglo XV por Alonso de Cartagena, obispo de Burgos.

XLVIII. «Las flores de los morales de Job /»159:

Se corresponde con el libro $\mathrm{n} .{ }^{\circ}$ XLVII del Inventario: «Las flores de los morales de Job /» ${ }^{160}$ y con la obra n. 19 del Catálogo: «Los prólogos de San Gregorio, escritos en / romance, en papel, de mano, en 240 hojas / $/{ }^{161}$. Identificado con el documento con la signatura: BNE, MSS/12720, que contiene un ejemplar, en lengua castellana, copiado por Martín Sánchez de Tricio, escriba del primer conde de Haro, de las Flores de los Morales de S. Gregorio, escritas por Pero López de Ayala. Se trata de un códice del siglo XV, en papel, en el que se compendian los tres tomos de Los Morales de Job.

XLIX. «La primera y cuarta partida, en un volumen /» 162 :

Se corresponde con el libro n. ${ }^{\circ}$ XLIX del Inventario: «La primera e quarta partida, en un volumen /»163 y con la obra $\mathrm{n} . .0132$ del Catálogo: «Las siete partidas del señor rey don Alonso / el Savio, comenzadas víspera de San Juan Bap- / -tista, en

\footnotetext{
155 BNE, RES/141, fol. 21r.

56 AHVC, Ordenanzas del Hospital, fol. 18r.

7 BNE, RES/141, fols. 21r-21v.

BNE, RES/141, fols. $18 \mathrm{r}-18 \mathrm{v}$.

AHVC, Ordenanzas del Hospital, fol. 18r.

BNE, RES/141, fol. 21v.

BNE, RES/141, fol. 2v.

AHVC, Ordenanzas del Hospital, fol. 18r

163 BNE, RES/141, fol. 21v.
} 
la era de la Encarnación de Nuestro / Señor de 1251 años romanos y 152 días, mas / fue acavado en siete años; está en el cuerpo / la primera y quarta partidas, escritas de ma- / -no, en papel, sin glosa ninguna /»164. Identificado con el documento con la signatura: BNE, MSS/12793, que contiene un ejemplar, en lengua castellana, de las Siete Partidas, otorgadas por Alfonso X. Se trata de un manuscrito del siglo XIV, en papel, iluminado. En su primer volumen, contiene la primera y la cuarta partida.

L. «La segunda y tercera y setena partida, en un volumen / (18v)»165:

Se corresponde con el libro $n .{ }^{\circ} \mathrm{L}$ del Inventario: «La segunda e tercera e setena partida, en / un volumen / ${ }^{166}$ y con las siguientes obras del Catálogo: la $\mathrm{n} .{ }^{\circ}$ 133: «La tercera partida está escrita en papel, de / mano, sin glosa /»167; la n. 134: «La segunda, está escrita de mano, sin glosa / (15v)» ${ }^{168}$; y la n.ำ136: «La séptima partida está escrita de mano, en / papel, sin número de hojas /»169. Identificado, de una manera tentativa, con el documento con la signatura: BNE, MSS/12793, antes referido, que contiene, en su segundo volumen, la segunda y la tercera partida.

LI. «La quinta y sexta partida, en un volumen.» ${ }^{170:}$

Se corresponde con el libro $n .{ }^{\circ}$ LI del Inventario: «La quinta e sexta partida, en un volumen /» ${ }^{171}$ y con las siguientes obras del Catálogo: la n. 135: «La quinta y sexta partidas están escritas / de mano, en papel, sin número de hojas, en libro / de por sí /»172 y la n. 137: «Está en otro libro la sexta partida, muy vieja, / que está duplicada con la de arriva / $/ 173$. Identificado con el documento con la signatura: BNE, MSS/12793, antes citado, que contiene, en su tercer volumen, la quinta y la sexta partida, y con el documento con la signatura: BNE, MSS/12897, que contiene un ejemplar, en lengua castellana, de la sexta partida. Este documento se trata de un códice del siglo XIV, en papel, iluminado.

\section{LII. «En (sic) Julio Fronti- / -no /»174:}

Se corresponde con el libro n. LII del Inventario: «Julio Frontino /» ${ }^{175}$ y con la obra n. 110 del Catálogo: «Julio Frontino, que trata de diversas mañas / y exemplos para el capitán sobre lo que ha de / hacer antes de entrar en la batalla, en el primero / libro; en el segundo, de las cosas que se han / de hacer en la batalla; y en el tercero, de cómo / se han de combatir las ciudades; en el quarto, / de las co-

\footnotetext{
164 BNE, RES/141, fol. 15r.

5 AHVC, Ordenanzas del Hospital, fol. 18r.

BNE, RES/141, fol. 21v.

BNE, RES/141, fol. 15r.

BNE, RES/141, fol. 15r.

BNE, RES/141, fol. 15v.

AHVC, Ordenanzas del Hospital, fol. 18v.

BNE, RES/141, fol. 21v.

BNE, RES/141, fol. $15 \mathrm{v}$.

BNE, RES/141, fol. 15v.

AHVC, Ordenanzas del Hospital, fol. 18v.

175 BNE, RES/141, fol. 21v.
} 
sas que son semejantes a la distinción / de los primeros echos; y después trata, por tre- / -inta y seis reglas, de las batallas; y al fin / escrive una carta de loas de los capitanes de la / guerra; todo escrito de mano, en romance / $>^{176}$. Identificado con el documento con la signatura: BNE, MSS/9253, que contiene un ejemplar, cuya traducción en lengua castellana se atribuye a Diego Guillén de Ávila, de las Estratagemas, escritas por Sexto Julio Frontino. Se trata de un manuscrito del siglo $\mathrm{XV}$, en papel.

LIII. «La comedia y proberbios del marqués de Santilla- / -na y Jul[i]o de Mazica, en un volumen / $\gg 177$ :

Se corresponde con el libro n. LIII del Inventario: «La comedia e provervios de

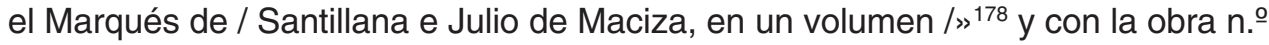
154 del Catálogo: «Las cien moralidades de Yñigo López de / Mendoza, señor de la Vega, con sus glosas e / historias que las declaran; contiene también / la comedia de Ponza, que hizo el mismo / autor sobre la batalla que los señores re- / yes de Aragón y Navarra y príncipes tu- / -bieron con los ginoveses; y al fin, a Julio de / Amatia, en romance, escrito de mano / $/ 179$. Se encuentra sin identificar.

LIV. «Salustio /»180:

Se corresponde con el libro n. LIV del Inventario: «Salustio /»181 y, como ten-

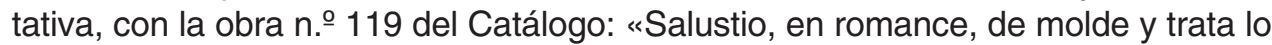
/ mismo /»182, considerando que la indicación «de molde» es equívoca. De tal manera, se identifica con el documento con la signatura: BNE, MSS/8724, que contiene un ejemplar, traducido en lengua castellana hacia 1450 por Vasco de Guzmán, de la Conjuración de Catilina y Guerra de lugurta, escrita por Cayo Salustio Crispo. Se trata de un códice, en papel.

LV. «Petrarca, de vita solitari (sic) /»183:

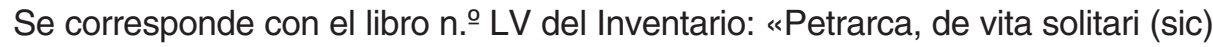
/» ${ }^{184}$ y con la obra n. ${ }^{\circ} 107$ del Catálogo: «Flores y sentencias del maestro Francisco / Petrarca, en el qual loa la vida apartada, lla- / -mada solitaria, escrito de mano / $>{ }^{185}$. Identificado con el documento con la signatura: BNE, MSS/9223, que contiene un ejemplar, cuya traducción en lengua castellana ha sido atribuida a Pero Díaz de Toledo, del De vita solitaria, escrito por Francesco Petrarca. Se trata de un manuscrito del siglo XV, en papel.

176 BNE, RES/141, fol. 12v.

7 AHVC, Ordenanzas del Hospital, fol. 18v.

178 BNE, RES/141, fol. 21v.

9 BNE, RES/141, fol. $18 \mathrm{v}$.

180 AHVC, Ordenanzas del Hospital, fol. 18v.

181 BNE, RES/141, fol. 21v.

182 BNE, RES/141, fol. 13v.

${ }^{183}$ AHVC, Ordenanzas del Hospital, fol. 18v.

184 BNE, RES/141, fol. 21v.

185 BNE, RES/141, fol. 12r. 
LVI. «Luerco (sic), de consolación /»186:

Se corresponde con el libro n. ํ LVI del Inventario: «Boecio, de consolación /»187 y con la obra n. 100 del Catálogo: «Boecio, de consolación, escrito de mano, por / capítulos, en cinco libros /» ${ }^{188}$. Se encuentra sin identificar.

LVII. «Ioan Gallens /»189:

Se corresponde con el libro n.ํ LVII del Inventario: «Joan Gallens /»190 y con la obra n. 127 del Catálogo: «Tratado de suma de colaciones o ayun- / -tamientos, dividido en siete partes y distincio- / -nes: en la primera trata de la comunidad ge/ (14v) -neral y de las personas que la hazen; en la / segunda, del cuerpo de la comunidad y de las partes / que le constituyen, y cómo el príncipe se ha de aver / con todos y del gouierno general y particular; / en la tercera distinción se trata de la virtuosa / conversación con los adversarios y virtuosa vi- / -da de los hombres y mugeres en todos estados; / en la quarta y en las demás, de los depart(t)imientos / de los hombres y de su sustentación, posesiones / y riquezas. Está escrito de mano, en romance, / en 178 hojas /»191. Se encuentra sin identificar.

LVIII. «loan Vocacio /»192:

Se corresponde con el libro n. ${ }^{\circ}$ LVIII del Inventario: «Joan Bocacio / ${ }^{193}$ y con la obra n. 129 del Catálogo: «Joan Bocacio, que trata de las caydas que / en este mundo dieron muchos y mui grandes / hombres, porque nadie se ensovervezca con la / dichosa fortuna, escrito de mano, en 95 ojas; / y al fin de él otros capítulos de los doce savios / que el rey don Fernando de Castilla y León / mandó venir a sus reynos para le aconsejar / (15r) en lo espiritual y temporal, y cómo le dejaron / instrucción de las cosas que todo príncipe debe / haver en sí y cómo debe regir y castigar a los / de su reyno / $/{ }^{194}$. Identificado con el documento con la signatura: BNE, MSS/12733, que contiene un ejemplar, traducido en lengua castellana por Pero López de Ayala, del De casibus virorum illustrium, escrito por Giovanni Boccaccio. Se trata de un códice del siglo XV, en papel.

LIX. «La corónica abrebiada de los emperadores /»195:

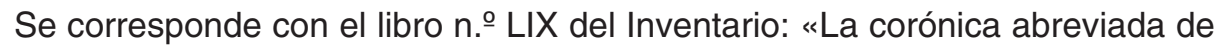
los emperadores /»196 y con la obra n. 143 del Catálogo: “Chrónica abreviada de los emperadores, re- / -yes y cónsules de Roma, en que hay 237 títu- / -los, escri-

\footnotetext{
86 AHVC, Ordenanzas del Hospital, fol. 18v.

7 BNE, RES/141, fol. 21v.

8 BNE, RES/141, fol. 11v.

9 AHVC, Ordenanzas del Hospital, fol. 18v.

BNE, RES/141, fol. 21v.

BNE, RES $/ 141$, fols. $14 r-14 v$.

AHVC, Ordenanzas del Hospital, fol. 18v.

BNE, RES/141, fol. 21v.

BNE, RES/141, fols. $14 \mathrm{v}-15 \mathrm{r}$.

AHVC, Ordenanzas del Hospital, fol. 18v.

196 BNE, RES/141, fol. 21v.
} 
tos de mano. El primero libro trata de / la chrónica y historia de España y cómo se divi- / -dieron los lenguages, y al fin está la chrónica / de todos los reyes de Castilla, hasta el señor / rey don Enrrique, padre del señor rey don / Juan, que fueron quarenta reyes en 660 años. / Y al fin están las ordenanzas que hizo el señor / rey don Enrrique en Segovia, año de $1406 />^{197}$. Se encuentra sin identificar.

LX. «Valerio Máximo /»198:

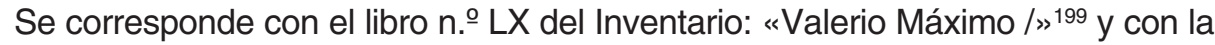
obra n. 91 del Catálogo: «Valerio Máximo, historiador, escrito en ro- / -mance, de mano, en papel. Trata de historias / romanas y otras materias / $/ 200$. Identificado con el documento con la signatura: BNE, MSS/9132, que contiene un ejemplar, traducido en lengua castellana, cuyo traductor es anónimo, de los Hechos y dichos memorables, escritos por Publio Valerio Máximo. Se trata de un manuscrito del siglo XIV/XV, en papel.

LXI. «Lucano /»201:

No presenta correspondencia con libro alguno del Inventario y se corresponde con la obra $n$. 90 del Catálogo: «Lucano, sobre las batallas de los empera- / -dores Julio César y Pompeyo y otras muchas / cosas hasta la venida de Nuestro Señor Jesu- / -christo, escrito de mano, en 217 ojas de papel /»202. Identificado con el documento con la signatura: BNE, MSS/12721, que contiene un ejemplar, en lengua castellana, cuyo traductor es anónimo, de la Pharsalia, escrita por Marco Anneo Lucano. Se trata de un códice del siglo XV, en papel.

LXII. «Vita Christi de fray Jermes (sic) Ximenes /»203:

Se corresponde con el libro n. ${ }^{\circ}$ LXI del Inventario: «Vita Christi de fray Ferres Ximenes $/{ }^{204} \mathrm{y}$, de una manera tentativa, con las siguientes obras del Catálogo: la $\mathrm{n}$. 11: «Volumen de la vida de Christo y otros san- / -tos, escrito en pargamino, de mano, en romance. / Fáltanle ojas al principio y al fin, y no tiene autor / (2v)»205 y la $\mathrm{n}$. $\mathrm{12}$ (del que forma parte la obra anterior): «Vn flos santorum, escrito de mano, en parga- / -mino, en 233 ojas /»206. De dicha manera, se identifica con el documento con la signatura: BNE, MSS/12688, que contiene un ejemplar del siglo XV, cuya traducción en lengua castellana ha sido atribuida a fray Gonzalo de Ocaña, de la Legenda aurea, escrita por el beato Jacopo della Voragine, y con el documento con la signatura: BNE, MSS/12689, que incluye otro ejemplar, de la misma

\footnotetext{
197 BNE, RES/141, fol. 16r.

8 AHVC, Ordenanzas del Hospital, fol. 18v.

9 BNE, RES/141, fol. 21v.

BNE, RES/141, fol. 10v.

AHVC, Ordenanzas del Hospital, fol. 18v.

BNE, RES/141, fol. 10v.

AHVC, Ordenanzas del Hospital, fol. 18v.

BNE, RES/141, fol. 21v.

BNE, RES/141, fol. $2 r$.

BNE, RES/141, fol. 2v.
} 
centuria, cuya traducción en lengua castellana también se atribuye a fray Gonzalo de Ocaña, de la Legenda aurea. Este libro contiene una compilación de relatos hagiográficos.

LXIII. «Vergel de consolación /»207:

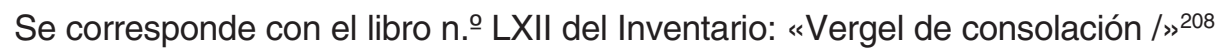
y con la obra n. 64 del Catálogo: «Vergel de consolación del alma, en 119 ca- / pítulos; trata de las virtudes que el hombre ha de / tener y de los pecados que deve aborrecer; escrito / de mano, en romance, sin autor /»209. Identificado con el documento con la signatura: BNE, MSS/9447, que contiene un ejemplar, traducido en lengua castellana por fray Jacobo de Benavente, del Viridarium consolationis, atribuido a San Buenaventura. Se trata de un manuscrito del siglo XV, en papel.

LXIV. «La glosa del regimiento de los príncipes y el libro / que fizo mesén (sic) Diego de Valera, en un volumen /»210:

Se corresponde con el libro $n .{ }^{\circ}$ LXIII del Inventario: «La glosa del regimiento de los príncipes e / (22r) el libro que fizo mosén Diego de Valera, en un volumen /»211 $\mathrm{y}$, como tentativa, con la obra $\mathrm{n} . \stackrel{\circ}{156}$ del Catálogo: «Tratado de las ceremonias de prínci- / -pes y, en este cuerpo, una carta en romance, / con otras escritas al rey, y una oración / en latín echa por don Juan Jufré de Ember- / -gense (sic), embajador de los señores duques de / Borgoña, al señor rey don Alonso de Por- / -tugal, escrito de mano / $/ 212$. De tal manera, se identifica con el documento con la signatura: BNE, MSS/1159, que contiene un ejemplar, en lengua castellana, del Ceremonial de príncipes, escrito por Diego de Valera, y un ejemplar, traducido en lengua castellana por Martín de Ávila, del Oratio ad Alfonsum V Lusitaniae regem, escrito por Jean Jufre d'Auvergne. Se trata de un códice del siglo XV, en papel.

LXV. «El libro del li[ce]nciado de Santo [A]gostín /»213:

Se corresponde con el libro n. ${ }^{\circ}$ LXIV del Inventario: «El libro del licenciado de

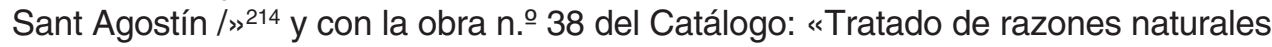
y dichos de / santos /»215. Identificado con el documento con la signatura: BNE, MSS/9477, que contiene un ejemplar, en lengua castellana, del Libro del regimiento de señores, escrito por Juan de Alarcón, OSA. Se trata de un manuscrito del siglo $\mathrm{XV}$, en papel. Su primer folio presenta el título siguiente: «Libro del Licenciado de Sant Agustín».

\footnotetext{
207 AHVC, Ordenanzas del Hospital, fol. 18v.

208 BNE, RES/141, fol. 21v.

BNE, RES/141, fol. 6v.

AHVC, Ordenanzas del Hospital, fol. 18v.

BNE, RES/141, fols. 21v-22r.

BNE, RES/141, fol. 19r.

AHVC, Ordenanzas del Hospital, fol. 18v.

BNE, RES/141, fol. 22v.

5 BNE, RES/141, fol. 4r.
} 


\section{LXVI. «El libro de San Gerónimo /»216:}

Se corresponde con el libro n. LXV del Inventario: «El libro de San Gerónimo /»217 y con la obra n. .36 del Catálogo: «Tratado de epístolas de Eusevio, que es- / -crivió al obispo de Damasco y a Theodosio, senador / romano, sobre la muerte de San Hierónimo y las / doctrinas que dio al tiempo de su muerte y los mi- / -lagros que Dios obró por él. Está escrito de mano, / en romance, en 75 hojas / $/{ }^{218}$. Identificado con el documento con la signatura: BNE, MSS/9235, que contiene un ejemplar, en lengua castellana, cuyo traductor es anónimo, de las Epístolas de Eusebio sobre la muerte y milagros de San Jerónimo. Se trata de un códice del siglo $\mathrm{XIV/XV}$, en papel.

LXVII. «El regimiento de los príncipes, glosado, en que fallece / el tercero libro /»219:

Se corresponde con el libro n. XXVI del Inventario: «El regimiento de los príncipes, glosado, en / que fallece el tercero libro / /220 y con la obra n. 0115 del Catálogo: «Tratado del regimiento de príncipes de don / fray Gil de Roma, trasladado en romance por / orden de don Bernardo, obispo de Osma, para / enseñamiento del señor rey don Pedro, hijo de el / señor rey don Enrrique / $/ 2^{221}$. Identificado con el documento con la signatura: BNE, MSS/12904, que contiene un ejemplar, en lengua castellana, comentado por Juan García de Castrojeriz, OFM, de los dos primeros volúmenes del Regimiento de príncipes. Se trata de un manuscrito del siglo XIV, en papel.

LXVIII. «La corónica del rey don Fernando, que ganó a Sebilla, y del / rey don Alonso, su fijo, y del rey don Sancho, su nieto / $>222$ :

Se corresponde con el libro n. LXVII del Inventario: «La corónica del rey don Fernando, que ga- / -nó a Sevilla, e del rey don Alonso, su fijo, / e del rey don Sancho, su nieto / $/ 223$ y con la obra n. .155 del Catálogo: "Chrónica del señor rey don Fernando, / hijo de los señores rey don Alonso <de León> y doña / (19r) Berenguela, escrito en 106 capítulos, / hasta el año de 1252; y en el mismo li- / -bro está la chrónica del señor rey don / Alonso, su hijo, rey de Castilla y de León, / que trata de las tierras que ganó a los mo- / -ros y de su testamento; y de el señor rey / don Sancho /»224. Identificado con el documento con la signatura: BNE, MSS/9233, que contiene un ejemplar, en lengua castellana, de la Crónica de Fernando III el

\footnotetext{
216 AHVC, Ordenanzas del Hospital, fol. 18v.

217 BNE, RES/141, fol. 22r.

8 BNE, RES/141, fol. 4r.

9 AHVC, Ordenanzas del Hospital, fol. 18v.

BNE, RES $/ 141$, fol. 22r.

BNE, RES/141, fol. 13r.

AHVC, Ordenanzas del Hospital, fol. 18v.

BNE, RES/141, fol. 22r.

4 BNE, RES/141, fols. 18v-19r.
} 
Santo, y otro ejemplar, en lengua castellana, de las Crónicas de Alfonso $X$ y Sancho IV. Se trata de un códice del siglo XIV/XV, en papel.

LXIX. «La corónica del rey don Alonso, padre del rey don / Juan.»225:

Se corresponde con el libro $n .^{\circ}$ LXVIII del Inventario: «La corónica del rey don Alonso, padre de / el rey don Juan /»226, aunque no se corresponde con obra alguna del Catálogo. Se encuentra sin identificar.

LXX. «La segunda parte de la corónica del rey don Rodri- / -go, de cómo se perdió la tierra /»227:

Se corresponde con el libro n. LXIX del Inventario: «La segunda parte de la

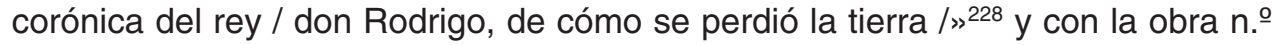
139 del Catálogo: «Chrónica antigua de España y de su perdición, / escrita de mano, sin principio ni fin porque fal- / -tan las once hojas primeras y las últimas $1 \gg 229$. Se encuentra sin identificar.

LXXI. «El libro de los padres /»230:

Se corresponde con el libro $n .{ }^{\circ}$ LXX del Inventario: «El libro de los padres /»231 y, como disyuntiva, con la obra $n$. o 42 del Catálogo: «Tratado de dichos de doctores, en lengua cas- / -tellana y latina, y cartas de santos y otras ad- / -vertencias, escrito de mano, en 142 hojas /»232, o bien, con el libro n. 51 del Catálogo: «La corona de los monges, con diversos dichos / de los padres, escrita de mano, por muchos ca- / -pítulos, sin autor / $/ 233$. La primera alternativa se encuentra sin identificar. La segunda, se identifica con el documento con la signatura: BNE, MSS/9247, que contiene un ejemplar, en lengua castellana, cuyo traductor se desconoce, de la Crónica de los monjes, con diversos dichos de Santos Padres y otros documentos. Se trata de un manuscrito del siglo XV, en papel.

LXXII. «El libro de las tres cre[e]ncias para contra los judíos /»234:

Se corresponde con el libro $n .{ }^{\circ} \mathrm{LXXI}$ del Inventario: «El libro de las tres creencias para con- / -tra los judíos /» ${ }^{235}$ y con la obra n. 963 del Catálogo: «Tratado de las tres creencias y de lo que / cada apóstol compuso sobre el símbolo y decla- / raciones echas sobre él, sin author, escrito de ma- / -no, en romance / (6v)»236.

\footnotetext{
225 AHVC, Ordenanzas del Hospital, fol. 18v.

26 BNE, RES/141, fol. 22r.

7 AHVC, Ordenanzas del Hospital, fol. 18v.

8 BNE, RES/141, fol. 22r.

BNE, RES/141, fol. 15v.

AHVC, Ordenanzas del Hospital, fol. 18v.

BNE, RES/141, fol. 22r.

BNE, RES/141, fol. 4r.

BNE, RES/141, fol. 5r.

AHVC, Ordenanzas del Hospital, fol. 18v.

BNE, RES/141, fol. 22r.

BNE, RES/141, fol. $6 r$.
} 
Identificado con el documento con la signatura: BNE, MSS/9302, que contiene un ejemplar, en lengua castellana, del Libro de las tres creencias, escrito por el converso Alfonso de Valladolid. Se trata de un códice del siglo XIV, en papel.

LXXIII. «Otro libro que fizo rabí Moysén de Egipto /»237:

Se corresponde con el libro $n .{ }^{\circ}$ LXXII del Inventario: «Otro libro que fizo rabí Mosén de Egipto /»238 y con la obra n. 74 del Catálogo: “Otro libro de rabá Mossé de Egipto contra / los judíos que niegan el advenimiento de Nu- / -estro Señor y prueva, con muchas razones, la ver- / -dad del verdadero Mexías; hízolas el maestro / Hierónimo de Santa Fee en presencia del papa / Benedicto XIV y de los cardenales y prelados, / maestros y doctores, en el año de 1412. Está / escrito de mano, en romance, en 12 capítulos / $/ 239$. Identificado, de una manera tentativa, con el documento con la signatura: BNE, MSS/10276, que contiene un ejemplar, en lengua castellana, de las Razones que expuso Jerónimo de Santa Fe ante Benedicto XIII y su corte, en agosto de 1412, probando contra los judíos el advenimiento del Mesías, escritas por el converso Jerónimo de Santa Fe. Se trata de un manuscrito del siglo XV, en papel. La alusión al papa «Benedicto XIV» (1740-1758) es equívoca.

LXXIV. «Otro libro que ficieron dos sabios judíos /»240:

Se corresponde con el libro $n .{ }^{\circ}$ LXXIII del Inventario: "Otro libro que ficieron dos sabios judíos /»241 y con la obra n. $\$ 77$ del Catálogo: «Carta tresladada de arábigo en latín, / escrito por rabbí Samuel de Ysrrael, de la ciudad / de Fez, del reyno de Marruecos, dirigida a ma- / -estre Isaac rabbí; contiene muchas dudas que / rabbí Samuel hizo sobre la Santa Escritura / y sobre su captividad y la de Bavilonia, y de- / -clara las siete peticiones del Pater Noster; de / mano, en romance /»242. Identificado con el documento con la signatura: BNE, MSS/9260, que incluye un ejemplar, traducido en lengua castellana en 1418 por el bachiller Álvaro de Villaescusa, de las Cartas del rabí Samuel de Fez y rabí Isaac de Subiulmeta. Se trata de un códice, en papel, de materia antijudaica.

LXXV. «El libro de los sabios /»243:

Se corresponde con el libro n. $\circ$ LXXIV del Inventario: «El libro de los savios /»244 y, como tentativa, con la obra n. 939 del Catálogo: «Otro tratado de dichos de santos sobre diver- / -sas materias, escrito en romance, en 56 ojas /»245. De dicha manera, se identifica con el documento con la signatura: BNE, MSS/9216, que con-

\footnotetext{
237 AHVC, Ordenanzas del Hospital, fol. 18v.

238 BNE, RES/141, fol. 22r.

239 BNE, RES/141, fol. 7v.

240 AHVC, Ordenanzas del Hospital, fol. 18v.

241 BNE, RES/141, fol. 22r.

242 BNE, RES/141, fol. 8r.

243 AHVC, Ordenanzas del Hospital, fol. 18v.

244 BNE, RES/141, fol. 22r.

245 BNE, RES/141, fol. 4r.
} 
tiene un ejemplar, traducido en lengua castellana por Pedro Gómez Barroso, del Libro del consejo y de los consejeros. Se trata de un manuscrito del siglo XV, en papel.

LXXVI. «El libro del bezerro, le (sic) pidió la señora duquesa ${ }^{246}$ en / 14 de diciembre de $1706 / 2247$ :

Se corresponde con el libro n. LXXV del Inventario: «El libro del bezerro / (22v) ${ }^{248}$ y con la obra n. ${ }^{1} 147$ del Catálogo: 'Libro del becerro, escrito de mano, en 436 / hojas. Es su prólogo: 'Libro de lo que fue fallado / quántos son los derechos de las merindades / de Carrión e de Campos e de Monzón e del / Ynfantazgo de Valladolid y de Zerrato, los / quales derechos fueron savidos por pesquisa / que ficieron por carta y mandado de nuestro / señor el rey don Alonso, Gonzalo Martínez / (17r) de Peñafiel e Lorenzo Martínez, clérigo de / Peñafiel; la qual pesquisa fue echa en cada lugar / de las dichas merindades, así reales como de ór- / -denes e abbadengos y solariegos e vehetrías e / de otros señores qualesquier, e de los derechos / que en cada lugar, por los dichos Gonzalo Martí- / -nez e Lorenzo Martínez, escrivano público, con / dos homes buenos que fueron tomados para esto / en cada lugar, juramentados sobre la cruz e / los Santos Evangelios, los quales derechos / son los que se siguen'. Hízose en la era de / 1390 años. No está signado ni authorizado $/ 2249$. Se encuentra sin identificar.

LXXVII. «El libro del seguro de Otordesillas (sic) /»250:

Se corresponde con el libro $\mathrm{n} .$. LXXVI del Inventario: «El libro del seguro de Oterdesillas (sic) /»251 y con la obra n.․ 151 del Catálogo: «Libro de seguro y salvoconducto y de la entrada / y salida de Tordesillas, donde se refieren muchas / grandezas que el señor conde de Haro hizo y lo / que trató con el señor rey don Juan, y de el / buen efecto que todo tubo en el año de 1439; / escrito de mano, en 148 hojas, tiene 84 capí- / -tulos. Mandole llevar su Excelencia /»252. Identificado con el documento con la signatura: BNE, MSS/9224, que contiene un ejemplar, en lengua castellana, del Seguro de Tordesillas, escrito por Pedro Fernández de Velasco, primer conde de Haro. Se trata de un códice del siglo XV, en papel.

LXXVIII. «Árbol de batallas /»253:

Se corresponde con el libro n. ${ }^{\circ}$ LXXVII del Inventario: «Árbol de batallas $/ » 254$ y con la obra n. 95 del Catálogo: «Vn árbol de batallas, escrito en lengua / francesa,

\footnotetext{
246 Vid. n. 14.

7 AHVC, Ordenanzas del Hospital, fol. 18v.

8 BNE, RES/141, fol. 22r.

BNE, RES/141, fols. 16v-17r.

AHVC, Ordenanzas del Hospital, fol. 18v.

BNE, RES/141, fol. 22V.

BNE, RES/141, fol. $18 \mathrm{r}$.

AHVC, Ordenanzas del Hospital, fol. 18v.

254 BNE, RES/141, fol. 22v.
} 
de mano, en pergamino, iluminado, / en 99 hojas /»255. Identificado con el documento con la signatura: BNE, VITR/24/13, que contiene un ejemplar, en lengua francesa, del Arbre des batailles, escrito por Honoré Bouvet. Se trata de un manuscrito francés del siglo XIV, en pergamino, ricamente miniado.

LXXIX. «El libro de las cuestiones /»256:

Se corresponde con el libro $n .^{\circ}$ LXXVIII del Inventario: «El libro de las questiones /»257 y con la obra $n .{ }^{\circ} 112$ del Catálogo: «Libro intitulado de las questiones, escrito / en lengua estrangera / $/ 258$. Identificado con el documento con la signatura: BNE, MSS/9270, que contiene un ejemplar, en lengua francesa, de Les Demandes de la chevalerie, escritas por Geoffroi de Charny. Se trata de un códice francés del siglo XIV, en pergamino, iluminado.

LXXX. «Las contemplaciones /»259:

Se corresponde con el libro $n .^{\circ}$ LXXIX del Inventario: «Las contemplaciones /»260 y con la obra n. 50 del Catálogo: «Contemplaciones de San Agustín, en un / libro escrito en lengua francesa /»261. Identificado con el documento con la signatura: BNE, MSS/9449, que contiene un ejemplar, en lengua francesa, de Les Contemplations, escritas por San Agustín. Se trata de un manuscrito francés del siglo $\mathrm{XV}$, en pergamino, con miniaturas.

\section{CLASIFICACIÓN DE LOS LIBROS DONADOS POR EL PRIMER CONDE DE HARO AL HOSPITAL DE LA VERA CRUZ DE MEDINA DE POMAR}

El documento fundacional del Hospital de la Vera Cruz de Medina de Pomar fue otorgado el 13 de diciembre de 1438 por Pedro Fernández de Velasco en la mencionada villa. Unos años más tarde, el 14 de agosto de 1455, el primer conde de Haro concedía en Valladolid el documento relativo a las ordenanzas del hospital. Siguiendo las disposiciones de tales ordenanzas, podemos destacar aquélla en la que el conde donaba a la institución asistencial una dotación de obras, la cual era considerada por el magnate como la más apropiada para los fines devocionales del hospital.

En la conformación de la referida dotación hay que señalar la influencia ejercida por Alonso de Cartagena, obispo de Burgos. Dicha influencia es manifiesta en

\footnotetext{
55 BNE, RES/141, fol. 10v.

AHVC, Ordenanzas del Hospital, fol. 18v.

BNE, RES/141, fol. 22v.

BNE, RES/141, fol. 12v.

9 AHVC, Ordenanzas del Hospital, fol. 18v.

BNE, RES/141, fol. 22v.

261 BNE, RES/141, fol. $5 r$.
} 
su libro: Epistula directa ad inclitum et magnificum virum dominum Petrum Fernandi de Velasco, Comitem de Haro'62, escrito hacia 1440. En los capítulos I-V, propone que los hombres se dividen en los grupos siguientes: los que no leen, los scholastici viri y los del medium genus (en el que se encontraría el conde), los cuales combinan los dos extremos de la vida humana: la activa y la contemplativa. En los capítulos VI-VII, define el programa de lecturas apropiado para el grupo del medium genus, con objeto de que alcance la verdadera sabiduría. Considera que los criterios que deben gobernar la elección de las obras son los siguientes: que sean sanos para el espíritu, saludables moralmente y que se encuentren ajustados a la capacidad del lector. Y en los capítulos VIII-X, efectúa la aplicación práctica de los citados criterios. Según el primer criterio, acepta únicamente aquellos libros que respeten los dogmas del credo católico. Teniendo presente el segundo criterio, censura aquellas obras de asunto obsceno y ficticio. Según el tercer criterio, considera que las especulaciones acerca de las incognitae res deben concernir a los scholastici viri.

De la colección he anotado ochenta libros, de los cuales han sido identificados y glosados sesenta y cuatro, si bien la identificación de trece de ellos la he realizado de una manera tentativa.

Asimismo, podemos indicar, a modo de propuesta, una clasificación de las obras según las materias siguientes: Sagrada Escritura, teológica, ascético-formativa, litúrgica, piadosa, profana, jurídica e histórica.

Han sido identificadas ocho obras sobre la Sagrada Escritura en los libros, incluidos en el documento que he transcrito, con la numeración siguiente: I, II, III, XI, XXXVI, XXXVII, XXXVIII y XLVIII.

He identificado cuatro obras teológicas en los libros siguientes: LXVI, LXXII, LXXIII y LXXIV, aunque la identificación del número LXXIII la he efectuado a modo de conjetura.

Han sido identificadas diez obras ascético-formativas en los libros con la numeración siguiente: IV, VI, XIII, XIX, XXXV, XLIV, LV, LXIII, LXV y LXXX.

He identificado siete obras litúrgicas en los libros siguientes: XXII, XXIV, XXV, XXVI, XXVII, XXIX y XXX, si bien la identificación de los números XXIV, XXVII, $X X I X$ y $X X X$ la he realizado de una manera tentativa.

Han sido identificadas once obras piadosas en los libros con la numeración siguiente: V, VII, VIII, XII, XVIII, XX, XXXII, LVIII, LXII, LXXI y LXXV, aunque la identificación de los números LXII, LXXI y LXXV la he efectuado como una conjetura.

He identificado once obras profanas en los libros siguientes: IX, XV, XVII, XXXIII, XXXIV, XL, LII, LXIV, LXVII, LXXVIII y LXXIX, si bien la identificación de los números $X L$ y LXIV la he realizado de una manera tentativa.

262 BNE, MSS/9208, fols. 1r-26r. 
Han sido identificadas cinco obras jurídicas en los libros con la numeración siguiente: XXXI, XLV, XLIX, L y LI, aunque la identificación del número L la he efectuado como conjetura.

He identificado ocho obras históricas en los libros siguientes: XLII, XLIII, XLVII, LIV, LX, LXI, LXVIII y LXXVII, si bien la identificación de los números XLVII y LIV la he realizado de una manera tentativa.

Se trata de una dotación de obras que nos presenta un modelo de mentalidad aristocrática del Cuatrocientos, representativa no sólo de los gustos del primer conde de Haro sino de la ideología de un movimiento cultural de la época, caracterizado por cultivar, principalmente, el campo de la devoción lega y secular.

La colección inicial de libros del Hospital de la Vera Cruz de Medina de Pomar, junto con la biblioteca de înigo López de Mendoza (1398-1458), primer marqués de Santillana, y la de Alonso de Pimentel (c. 1400-1461), tercer conde de Benavente, son consideradas, en la Castilla de mediados del siglo XV, testimonios de la bibliofilia de la alta nobleza y claves para la comprensión de la época llamada «fin de la Edad Media, o bien, pórtico del Renacimiento »263.

Tales colecciones nos ofrecen, como caracteres comunes, una conjunción entre el pensamiento estoico y el cristiano, una insistencia en los valores tradicionales y nobiliarios, y un regocijo del ideal de educación política de los príncipes y gobernantes representado por el género De regimine principum.

$Y$ en cuanto a las diferencias, hay que señalar las encontradas entre la dotación inicial de obras del hospital y la biblioteca del primer marqués de Santillana. Si la primera dotación se caracteriza por cultivar el campo de la devoción lega y secular, la segunda es considerada como el fundamento para el estudio del movimiento humanista y prerrenacentista.

\section{CONCLUSIÓN}

El 14 de agosto de 1455 Pedro Fernández de Velasco otorgaba al Hospital de la Vera Cruz de Medina de Pomar el documento de sus ordenanzas, de las que podemos señalar aquella en la que el primer conde de Haro donaba al hospital una colección de libros, la cual era valorada por el conde como la más adecuada para las necesidades de la institución asistencial.

En la configuración de la mencionada colección hay que indicar el influjo de Alonso de Cartagena, obispo de Burgos, en su obra: Epistula directa ad inclitum et magnificum virum dominum Petrum Fernandi de Velasco, Comitem de Haro, en la

${ }^{263}$ LAWRANCE, J. N. H., Op. Cit., pág. 1073. 
que aprueba los libros que acaten los fundamentos de la fe católica, rechaza las obras de asunto impúdico y fingido, y estima que las meditaciones sobre las incognitae res competen a los scholastici viri.

De la dotación he apuntado ochenta libros, de los cuales han sido identificados, comentados y clasificados sesenta y cuatro, aunque la identificación de trece de ellos la he efectuado como una tentativa.

La clasificación la he realizado en obras de materia religiosa, moral, profana, jurídica e histórica.

La colección de libros nos muestra un ejemplo de pensamiento nobiliario del Cuatrocientos, que se caracteriza por ejercitar, fundamentalmente, la devoción lega y secular.

La referida colección, la biblioteca del primer marqués de Santillana y la del tercer conde de Benavente, en la Castilla de mediados del siglo XV, testimonian la bibliofilia de la nobleza magnaticia y representan una clave para el entendimiento de dicha centuria. 